\title{
Optimizing Well-being, Practice Culture, and Professional Thriving in an Era of Turbulence
}

\author{
Read G Pierce, MD*; Manuel Diaz, MD; Patrick Kneeland, MD
}

Division of Hospital Medicine, Department of Medicine, University of Colorado School of Medicine, Aurora, Colorado.

n 2010, the Journal of Hospital Medicine published an article proposing a "talent facilitation" framework for addressing physician workforce challenges. ${ }^{1}$ Since then, continuous changes in healthcare work environments and shifts in relevant policies have intensified a sense of clinician workforce crisis in the United States, ${ }^{2,3}$ often described as an epidemic of burnout. Unfortunately, hospital medicine remains among the specialties most impacted by high burnout rates and related turnover. ${ }^{4-6}$

\section{THE HEALTHCARE TALENT IMPERATIVE}

Despite efforts to address the sustainability of careers in hospital medicine, common approaches remain mostly reactive. Existing research on burnout is largely descriptive, focusing on the magnitude of the problem, ${ }^{3}$ the links between burnout and diminished productivity or turnover, ${ }^{7}$ and the negative impact of burnout on patient care. ${ }^{8.9}$ Improvement efforts often focus on rescuing individuals from burnout, rather than prevention. ${ }^{10}$ While evidence exists that both individually targeted interventions (eg, mindfulness-based stress reduction) and institutional changes (eg, improvements in the operation of care teams) can reduce burnout, efforts to promote individuals' resilience appear to have limited impact. ${ }^{11,12}$

Given our field's reputation for innovation, we believe hospitalist groups must lead the way in developing practical solutions that enhance the well-being of their members, by doing more than exhorting clinicians to "heal themselves" or imploring executives to fix care delivery systems. In this article, we describe an approach to increase resilience and well-being in a large, academic hospital medicine practice and offer an emerging list of best practices.

\section{FROM BURNOUT TO WELL-BEING- A PARADIGM SHIFT}

Maslach et al. demonstrated that burnout reflects an individual's experience of emotional exhaustion, depersonalization of human interactions, and decreased sense of accomplishment

\footnotetext{
*Corresponding Author: Read G. Pierce, MD, E-mail: read.pierce@ucdenver edu; Telephone: 720-848-4289; Twitter: @piercereadg

Additional Supporting Information may be found in the online version of this article.
}

Received: March 15, 2018; Revised: September 28, 2018;

Accepted: September 14, 2018

(c) 2018 Society of Hospital Medicine DOI 10.12788/jhm.3101 at work. ${ }^{13}$ Updated frameworks emphasize that well-being and lower burnout arise from workflow efficiency, a surrounding culture of wellness, and attention to individual resilience. ${ }^{14}$ Emerging evidence suggests that burnout and well-being are, in part, a collective experience. ${ }^{15}$ As outlined in the recently published "Charter on Physician Well-being, "16 this realization creates an opportunity for clinical groups to enhance collective well-being —or thriving — rather than asking individuals to take personal responsibility for resilience or waiting for a top-down system redesign to fix drivers of burnout.

\section{APPLYING THE NEW PARADIGM TO HOSPITAL MEDICINE}

In 2013, our academic hospital medicine group set a new vision: To become the best in the nation by being an outstanding place to work. We held an inclusive divisional strategic planning retreat, which focused on clarifying the group's six core values and exploring how to translate the values into structures, processes, and behaviors that reinforced, rather than undermined, a positive work environment. We used these initial themes to create 16 novel interventions from 2014-2017 (Figure).

Notably, we pursued this work without explicit support or interference from senior leaders in our institution. There were no competing organizational efforts addressing hospitalist efficiency, turnover, or burnout until 2017 (Excellence in Communication, described below). Furthermore, we avoided individually targeted resilience efforts based on feedback from our group that "requiring resilience activities is like blaming the victim." Intervention participation was not mandatory, out of respect for individual choice and to avoid impeding hospitalists' daily work.

Before designing interventions, we created a measurement tool to assess our existing culture and track evolution over time (available upon request). We utilized the instrument to provoke emotional responses, surface paradoxes, uncover assumptions, and engage the group in iterative dialog that informed and calibrated interventions. The instrument itself drew from validated elements of existing tools to quantify perceptions across nine domains: meaningful work, autonomy, professional development, logistical support, health, fulfillment outside of work, collegiality, organizational learning, and safety culture.

Several subsequent interventions focused on the emotional experience of work. For example, we developed a formal mechanism (Something Awesome) for members to share the 


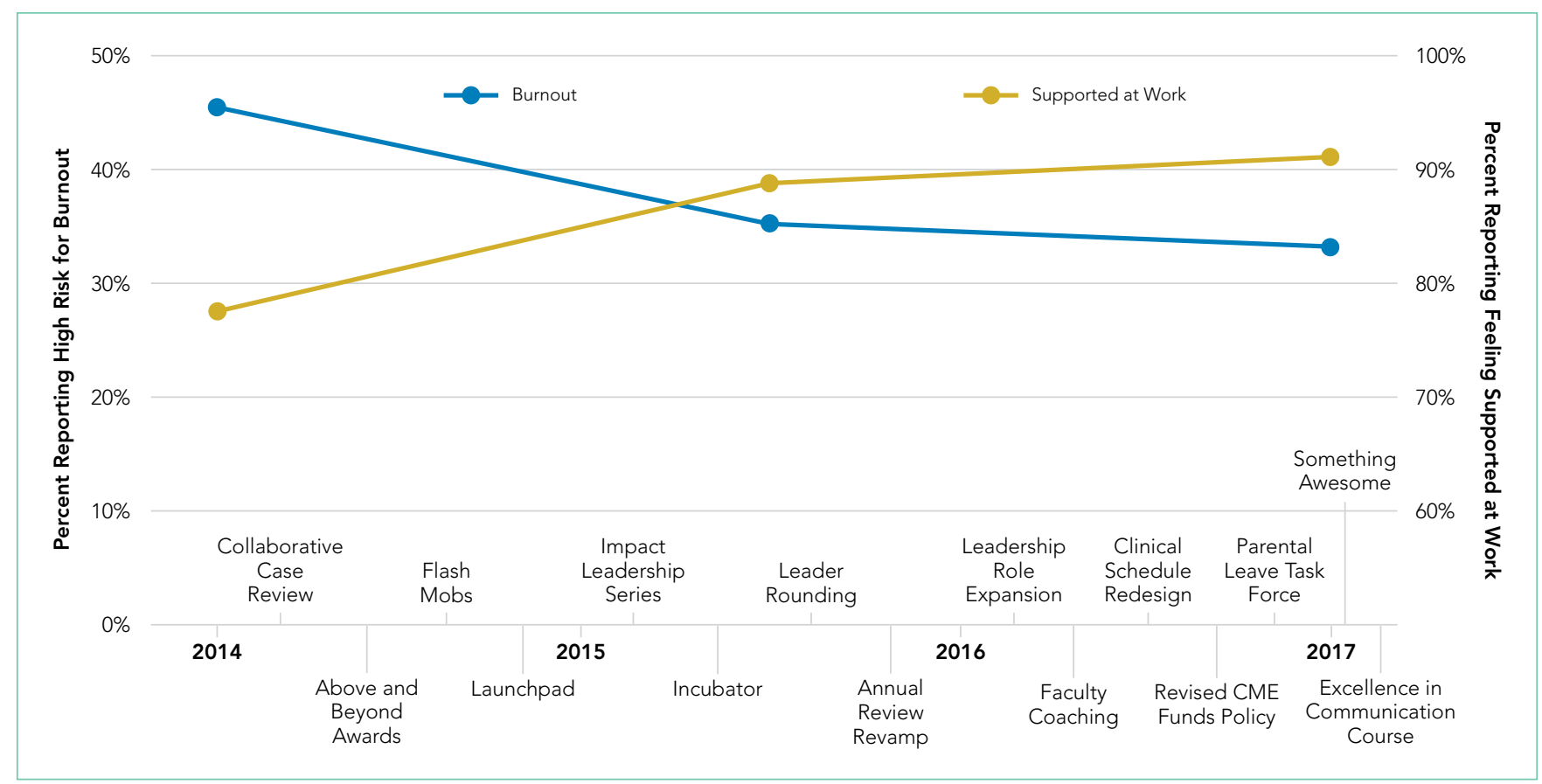

FIG. Interventions Made over Time to Enhance Resilience, Well-being, and Burnout.

experience of positive emotions during daily work (eg, gratitude and awe) for five minutes at monthly group meetings. We created a Collaborative Case Review process, allowing members to submit concerning cases for nonpunitive discussion and coaching among peers. Finally, we created Above and Beyond Awards, through which members' written praise of peers' extraordinary efforts were distributed to the entire group.

We also pursued interventions designed to increase empathy and translate it to action. These included leader rounding on our clinical units, which sought to recognize and thank individuals for daily work and to uncover exigent needs, such as food or assistance with conflict resolution between services. We created "Flash Mobs" or group conversations, which are facilitated by a leader and convened in the hospital, in order to hear from people and discuss topics of concern in real time, such as increased patient volumes. Likewise, we established "The Incubator," a half-day meeting held four to six times annually when selected clinical faculty applied design thinking techniques to create, test, and implement ideas to enhance workplace experience (eg, supplying healthy food to our common work space at low cost).

Another key focus was professional development for group members. Examples included a three-year development program for new faculty (LaunchPad), increasing the number of available leadership roles for aspiring leaders, modifying annual reviews to focus on increasing individuals' strengths-based work rather than solely grading performance, and creating a peer-support coaching program for newly hired members. In 2017, we began offering members a full shift credit to attend the hospital's four-hour Excellence in Communication course, which covers six high-yield skills that increase efficiency, effica$c y$, and joy in practice.
Finally, we revised a number of structures and operational processes within our group's control. We created a task force to address the needs of new parents and acquired a lactation room in the hospital. Instead of only covering offsite conference attendance (our old policy), we enhanced autonomy regarding use of continuing education dollars to allow faculty to fund any activity supporting their clinical practice. Finally, we applied quality improvement methodology to redesign the clinical schedule. This included blending value-stream mapping, software solutions, and a values-based framework to analyze proposed changes through the lens of waste elimination, IT feasibility, and whether the proposed changes aligned with the group's core values.

\section{IMPACT ON GROUP CULTURE AND WELL-BEING}

We examined the impact of these tactics on workplace experience over a four-year period (Figure). In 2014, 30\% of group members reported psychological safety, $24 \%$ had become more callous toward people in their current job, and $45 \%$ were experiencing burnout. By 2017, 59\% felt a sense of psychological safety (69\% increase), $15 \%$ had become more callous toward people (38\% decrease), and 33\% were experiencing burnout (27\% decrease). Average annual turnover in the five years before the first survey was $13.2 \%$; turnover declined during the intervention period to $6.6 \%$ (adjusted for increased number of positions). While few comprehensive models exist for calculating well-being program return on investment, the American Medical Association's calculator ${ }^{17}$ demonstrated our group's cost of burnout plus turnover in 2013 was $\$ 464,385$ per year (assumptions in Appendix 1). We spent $\$ 343,517$ on the 16 interventions between 2013 and 2017, representing an aver- 
age annual cost of $\$ 86,000$ : $\$ 190,094$ to buy-down clinical time for new leadership roles, $\$ 133,023$ to fund time for the Incubator, $\$ 2,500$ on gifts and awards, $\$ 4,900$ on program supplies, and $\$ 10,000$ on leadership training.

\section{BEST PRACTICES FOR HOSPITALIST GROUPS}

Based on the current literature and our experience, hospital medicine groups seeking to improve culture, resilience, and well-being should:

- Collaborate to define the group's sense of purpose. Mission and vision are important, but most of the focus should be on surfacing, naming, and agreeing upon the group's essential core values - the beliefs that inform whether hospitalists see the workplace as attractive, fair, and sustainable. Utilizing an expert, neutral facilitator is helpful.

- Assess culture-including, but not limited to, individual burnout and well-being-using preexisting questions from validated instruments. As culture is a product of systems, team climate, and leadership, measurement should include these domains.

- Monitor and share anonymous data from the assessment regularly (at least annually) as soon as possible after survey results are available. The data should drive inclusive, open, nonjudgmental dialog among group members and leaders in order to clarify, explore, and refine what the data mean.

- Undertake improvement efforts that emerge from the steps above, with a balanced focus on the three domains of well-being: efficiency of practice, culture of wellness, and personal resilience. Modify the number and intensity of interventions based on the group's readiness and ability to control change in these domains. For example, some groups may have more excitement and ability to work on factors impacting the efficiency of practice, such as electronic health record templates, while others may wish to enhance opportunities for collegial interaction during the workday.

- Strive for codesign. Group members must be an integral part of the solution, rather than simply raise complaints with the expectation that leaders will devise solutions. Ideally, group members should have time, funding, or titles to lead improvement efforts.

- Opportunities to improve resilience and well-being should be widely available to all group members, but should not be mandatory.

\section{CONCLUSION}

The healthcare industry will continue to grapple with high rates of burnout and rapid change for the foreseeable future. We believe significant improvements in burnout rates and workplace experience can result from hospitalist-led interventions designed to improve experience of work among hospitalist clinicians, even as we await broader and necessary systematic efforts to address structural drivers of professional satisfaction. This work is vital if we are to honor our field's history of productive innovation and navigate dynamic change in healthcare by attracting, engaging, developing, and retaining our most valuable asset: our people.

Disclosures: The authors declare they have no conflicts of interest/competing interests.

\section{References}

1. Kneeland PP, Kneeland C, Wachter RM. Bleeding talent: a lesson from industry on embracing physician workforce challenges. J Hosp Med. 2010;5(5):306310. doi: 10.1002/jhm.594.

2. Farr C. Siren song of tech lures new doctors away from medicine. Shots. Health news from NPR. https://www.npr.org/sections/healthshots/2015/07/19/423882899/siren-song-of-tech-lures-new-doctors-awayfrom-medicine; July 19, 2015.

3. Shanafelt TD, Hasan O, Dyrbye LN, et al. Changes in burnout and satisfaction with work-life balance in physicians and the General US Working population between 2011 and 2014. Mayo Clin Proc. 2015;90(12):1600-1613. doi: 10.1016/j.mayocp.2015.08.023.

4. Roberts DL, Shanafelt TD, Dyrbye LN, West CP. A national comparison of burnout and work-life balance among internal medicine hospitalists and outpatient general internists. J Hosp Med. 2014;9(3):176-181. doi: 10.1002/ jhm.2146.

5. Vuong K. Turnover rate for hospitalist groups trending downward. The Hospitalist. http://www.thehospitalist.org/hospitalist/article/130462/turnover-rate-hospitalist-groups-trending-downward; 2017, Feb 1.

6. Hinami K, Whelan CT, Wolosin RJ, Miller JA, Wetterneck TB. Worklife and satisfaction of hospitalists: toward flourishing careers. J Gen Intern Med. 2012;27(1):28-36. doi: 10.1007/s11606-011-1780-z.

7. Dewa CS, Loong D, Bonato S, Thanh NX, Jacobs P. How does burnout affect physician productivity? A systematic literature review. BMC Health Serv Res. 2014;14:325. doi: 10.1186/1472-6963-14-325

8. Shanafelt TD, Balch CM, Bechamps G, et al. Burnout and medical errors among American surgeons. Ann Surg. 2010;251(6):995-1000. doi: 10.1097/ SLA.0b013e3181bfdab3.

9. Panagioti M, Geraghty K, Johnson J, et al. Association between physician burnout and patient safety, professionalism, and patient satisfaction: A systematic review and meta-analysis. JAMA Intern Med. 2018;178(10):13171330. doi: 10.1001/jamainternmed.2018.3713.

10. Hall LH, Johnson J, Watt I, Tsipa A, O'Connor DB. Healthcare staff wellbeing, burnout, and patient safety: A systematic review PLoS ONE. 2016;11(7):e0159015. doi: 10.1371/journal.pone.0159015.

11. Panagioti $M$, Panagopoulou $E$, Bower $P$, et al. Controlled interventions to reduce burnout in physicians: A systematic review and meta-analysis. JAMA Intern Med. 2017;177(2):195-205. doi: 10.1001/jamainternmed.2016.7674.

12. West CP, Dyrbye LN, Erwin PJ, Shanafelt TD. Interventions to prevent and reduce physician burnout: a systematic review and meta-analysis. Lancet. 2016;388(10057):2272-2281. doi: 10.1016/S0140-6736(16)31279-X.

13. Maslach C, Schaufeli WB, Leiter MP. Job burnout. Annu Rev Psychol. 2001;52:397-422. doi: 10.1146/annurev.psych.52.1.397.

14. Bohman B, Dyrbye L, Sinsky CA, et al. Physician well-being: the reciprocity of practice efficiency, culture of wellness, and personal resilience. NEJM Catalyst. 2017 Aug.

15. Sexton JB, Adair KC, Leonard MW, et al. Providing feedback following Leadership WalkRounds is associated with better patient safety culture, higher employee engagement and lower burnout. BMJ Qual Saf. 2018;27(4):261-270. doi: 10.1136/bmjqs-2016-006399.

16. Thomas LR, Ripp JA, West CP. Charter on physician well-being. JAMA. 2018;319(15):1541-1542. doi: 10.1001/jama.2018.1331.

17. American Medical Association. Nine Steps to Creating the Organizational Foundation for Joy in Medicine: culture of Wellness-track the business case for well-being. https://www.stepsforward.org/modules/joy-in-medicine. 